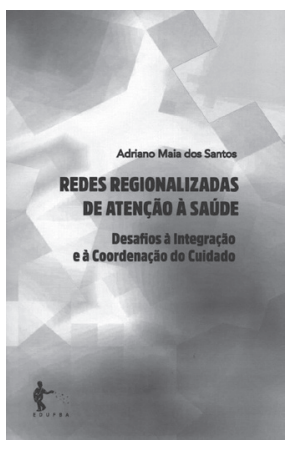

\title{
Santos AM. Redes regionalizadas de atenção à saúde: desafios à integração assistencial e à coordenação do cuidado
}

\author{
Raisa Santos Cerqueira1, Eduarda Ferreira dos Anjos', Nília Maria de Brito Lima Prado $\mathbf{1}$
}

DOI: $10.1590 / 0103-1104202112819$

'REDES REGIONALIZADAS DE ATENÇÃo À SAÚDE', produzido pela Edufba, editora da universidade em que Adriano Maia é docente e pesquisador, é fruto da tese de doutorado do autor. O livro traz reflexões extremamente pertinentes acerca dos desafios do acesso à saúde, do cuidado integral e da intercolaboração na perspectiva das redes regionalizadas. O texto é bastante convidativo, recomendado para gestores, formuladores de políticas, profissionais de saúde, estudantes em geral, em especial, da área da saúde coletiva.

A obra traz análise acurada e rigorosa sobre a experiência de organização da rede assistencial do Sistema Único de Saúde (SUS) em uma região de saúde da Bahia. Os dados são oriundos de pesquisa qualitativa bem delimitada com diferentes sujeitos da rede (gestores, profissionais e usuários). A metodologia bastante robusta é um ponto extremamente importante a ser ressaltado, pois apreende os aspectos gerais e singulares do tema, minimizando possíveis arestas. A contextualização histórica da regionalização resgata elementos fundamentais para compreensão do constructo e dialoga com os dados empíricos, a partir de ampla revisão de literatura nacional e internacionall.

A ideologia do pesquisador é bastante clara e, sem abandonar a visão epistemológica, trata do tema sob a ótica da Atenção Primária à Saúde (APS) abrangente e robusta, enquanto peça-chave no arranjo regional, para possibilitar um sistema de saúde público, universal e equânime. Tais aspectos tornam o trabalho extremamente atraente, dialético e desvela as iniquidades geradas pela lógica hegemônica do modelo biomédico do pensar/fazer saúde.

Organizado em seis capítulos, alocados em quatro partes, o livro segue a sistematização da pesquisa e proporciona fácil leitura e compreensão. O arranjo em quatro partes se apresenta da seguinte forma: I - 'Elementos teóricos para compreensão das redes de atenção à saúde'; II - 'Regionalização da saúde na Bahia: aspectos político-institucionais e modelagem dos territórios sanitários'; III - 'Gestão, organização e práticas em redes de atenção à saúde'; e IV - 'Linha de chegada e algumas considerações'”.

Na primeira parte, no capítulo I, são abordados os componentes estratégicos da regionalização para a gestão do cuidado em redes de atenção, versando sobre os diferentes atores, governamentais e não governamentais, para garantia da integralidade. Em seguida, o principal eixo discursivo constitui as redes de atenção à 
saúde e o status quo da APS, com importante resgate de aspectos políticos e históricos, inclusive a estruturação do nível de atenção em distintos países e no Brasil. Na sequência, analisa as contribuições teóricas da APS como coordenadora do cuidado nas redes de atenção à saúde e para integração assistencial no País. Discute, ainda, a organização das redes regionalizadas, reguladas não apenas na concepção racional, mas evidenciando a potência da APS enquanto porta de entrada, coordenadora e como ponto central de uma rede de atenção forte, organizada e resolutiva. A proposta é reforçada pela descrição de experiências exitosas de outros países, como estratégia para a implementação de ações com vistas à integralidade da atenção à saúde, considerando a complexidade dos municípios brasileiros.

A parte II, capítulo II, traz descrição da temporalidade dos fatos expostos em uma linha do tempo das políticas de saúde na Bahia, que inclui mais de quatro décadas, com análise crítica das mudanças governamentais, partidárias e ideológicas, bem como os impactos na saúde da população, destacando avanços e retrocessos. Recorre, ainda, à importância do arcabouço jurídico e normativo do SUS para a estruturação da política de regionalização em saúde, especificamente na Bahia'.

Na terceira parte, no capítulo III, o autor debate acerca da gestão, organização e das práticas em redes de atenção à saúde, desvelando suas nuances e complexidades. Nesse ponto, o leitor mergulha na rotina e na implementação da regionalização, através de análise crítica do papel das Comissões Intergestores Regionais (CIR). Falas contundentes de atores sociais implicados com a prática, intercaladas com exposição dos eixos estruturantes dessa instância, instauram uma série de inquietações acerca de: como está se dando o apoio do estado aos municípios; como o setor privado tem lançado mão de estratégias para permanecer inserido nas comissões, defendendo seus próprios interesses; e como o controle social vem se tornando frágil e sendo enfraquecido ao longo dos anos. Esses questionamentos tornam ainda mais ávido o desejo de desvendar a leitura.

No capítulo IV, o autor discorre sobre o papel primordial da Estratégia Saúde da Família (ESF) na região de saúde. As contribuições da teoria versus a prática permitem tecer críticas severas e importantes sobre aspectos estruturais e operacionais relacionados a falhas de comunicação, perfil e processo de trabalho dos profissionais vinculados ao modo de fazer saúde tecnicista e pouco resolutivo. As experiências e interações entre os sujeitos são reveladas por meio dos discursos dos usuários e profissionais, balizados pela exposição de fragilidades e contradições entre o cuidado em saúde e o direito à saúde, assim como o papel do Núcleo de Apoio à Saúde da Família (Nasf), entre outros. Destacam-se dificuldade de atração e fixação de profissionais na APS, falhas na formação para esse campo de trabalho, bem como obstáculos em reconhecer os diferentes tipos de tecnologias no cuidado em saúde, enfatizando os impactos desses problemas em um sistema biomédico.

Os fluxos assistenciais e dispositivos de integração e coordenação na rede regional de saúde são abordados no capítulo V. Os argumentos são sistematizados e problematizados por meio de questões sobre o subfinanciamento público do sistema, procedimentos de saúde centrados no profissional, práticas fragmentadas que poderiam conduzir à sobrecarrega do sistema. Além disso, o autor traz uma reflexão importante sobre a oferta e a procura do serviço especializado, as prioridades e dificuldades dos usuários, interferência do clientelismo e barganha política, especialmente nos municípios de pequeno porte, que desvelam processos que influenciam ou têm capacidade de restringir o acesso à saúde.

O texto salienta, ainda, questionamentos específicos de práticas concretas relatadas pelos usuários relacionados à prática médica, considerada autoritária. Tal situação é correlacionada com a fragilidade dos pontos de acesso aos serviços de média complexidade, 
evidenciando a reprodução de uma lógica produtivista, desarticulada da APS e que responsabiliza o usuário pelo seu trajeto assistencial e pela informação na rede. $\mathrm{O}$ texto apresenta, ainda, o descaso dos serviços especializados com os usuários, principalmente os mais vulneráveis, expostos a obstáculos derivados de processos frágeis, cuja terapêutica, na maioria das vezes, não reflete práticas integrais, cuidadosas e humanas.

No capítulo VI, uma abordagem didática dos distintos cenários possibilita ao leitor uma visão panorâmica da extensa pesquisa, com as características organizacionais dos quatro municípios, detalhamento do funcionamento da rede de atenção, da atenção básica e dos serviços de urgência, assim como as particularidades locais. Tal enfoque remete o leitor ao conteúdo teórico trazido inicialmente, sua interface com exemplos práticos (fluxograma) e contextualização com a realidade, aprofundada de forma intensa pelo pesquisador.
Por fim, na parte IV, o autor nos convida a refletir sobre o impacto desse estudo para o debate sobre a temática e a possibilidade de ressignificação das práticas (ainda que não seja um manual). Traz, também, empiricamente, uma série de experiências e robusto conteúdo teórico, com potencial contribuição para o modo de organização das políticas e para as condutas cotidianas nas regiões de saúde brasileiras. Em linhas gerais, a obra faz um chamado à luta por um SUS público e universal como forma de combate às iniquidades históricas criadas no País, que aposta nas pessoas e lhes dá dignidade e cidadania.

\section{Colaboradoras}

Cerqueira RS (0000-0002-9994-6394)*, Anjos EF (0000-0003-4322-236X)* e Prado NMBL (0000-0001-8243-5662)* contribuíram igualmente para a elaboração do manuscrito.

\section{Referência}

1. Santos AM. Redes regionalizadas de atenção à saúde: desafios à integração assistencial e à coordenação do cuidado. Salvador, Edufba; 2018.

Recebido em 14/07/2020

Aprovado em 19/11/2020

Conflito de interesses: inexistente

Suporte financeiro: não houve 